\title{
The National LGBT Cancer Action Plan: A White Paper of the 2014 National Summit on Cancer in the LGBT Communities
}

\author{
Jack E. Burkhalter, PhD, ${ }^{1, *}$ Liz Margolies, LCSW ${ }^{2,{ }^{*}}$ Hrafn Oli Sigurdsson, PhD, NP, PMHNP-BC, ${ }^{3}$ \\ Jonathan Walland, LLB, ${ }^{4}$ Asa Radix, MD, MPH, David Rice, RN, PhD, Francisco O. Buchting, PhD, \\ Nelson F. Sanchez, MD, Michael G. Bare, MPH, Ulrike Boehmer, PhD, ${ }^{10}$ Sean Cahill, PhD, ${ }^{11}$ \\ Tomas L. Griebling, MD, MPH, ${ }^{12}$ Diane Bruessow, PA-C, DFAAPA, ${ }^{13}$ and Shail Maingi, MD ${ }^{14}$
}

\begin{abstract}
Despite growing social acceptance of lesbians, gay men, bisexuals, and transgender (LGBT) persons and the extension of marriage rights for same-sex couples, LGBT persons experience stigma and discrimination, including within the healthcare system. Each population within the LGBT umbrella term is likely at elevated risk for cancer due to prevalent, significant cancer risk factors, such as tobacco use and human immunodeficiency virus infection; however, cancer incidence and mortality data among LGBT persons are lacking. This absence of cancer incidence data impedes research and policy development, LGBT communities' awareness and activation, and interventions to address cancer disparities. In this context, in 2014, a 2-day National Summit on Cancer in the LGBT Communities was convened by a planning committee for the purpose of accelerating progress in identifying and addressing the LGBT communities' concerns and needs in the spheres of cancer research, clinical cancer care, healthcare policy, and advocacy for cancer survivorship and LGBT health equity. Summit participants were 56 invited persons from the United States, United Kingdom, and Canada, representatives of diverse identities, experiences, and knowledge about LGBT communities and cancer. Participants shared lessons learned and identified gaps and remedies regarding LGBT cancer concerns across the cancer care continuum from prevention to survivorship. This white paper presents background on each of the Summit themes and 16 recommendations covering the following: sexual orientation and gender identity data collection in national and state health surveys and research on LGBT communities and cancer, the clinical care of LGBT persons, and the education and training of healthcare providers.
\end{abstract}

Key words: cancer, cancer disparities, lesbians, gay men, bisexuals, and transgender (LGBT).

\footnotetext{
${ }^{1}$ Department of Psychiatry and Behavioral Sciences, Memorial Sloan Kettering Cancer Center, New York, New York.

${ }^{2}$ National LGBT Cancer Network, New York, New York.

${ }^{3}$ Nursing Professional Development, Memorial Sloan Kettering Cancer Center, New York, New York.

${ }^{4}$ The Office of General Counsel, Memorial Sloan Kettering Cancer Center, New York, New York.

${ }^{5}$ Callen-Lorde Community Health Center, New York, New York.

${ }^{6}$ City of Hope, Duarte, California.

${ }^{7}$ Buchting Consulting, Oakland, California; Horizons Foundation, San Francisco, California.

${ }^{8}$ Department of Medicine, Memorial Sloan Kettering Cancer Center, New York, New York.

${ }^{9}$ Grassroots Change, Oakland, California.

${ }^{10}$ Department of Community Health Sciences, Boston University School of Public Health, Boston, Massachusetts.

${ }^{11}$ The Fenway Institute, Boston, Massachusetts.

${ }_{12}^{12}$ Department of Urology, School of Medicine, University of Kansas, Kansas City, Kansas.

${ }^{13}$ Healthy Transitions, LLC, Stirling, New Jersey.

${ }^{14}$ St. Peter's Health Partners Cancer Care, Troy, New York.

*Cofirst authors.

(c) Jack E. Burkhalter et al. 2016; Published by Mary Ann Liebert, Inc. This Open Access article is distributed under the terms of the Creative Commons Attribution Noncommercial License (http://creativecommons.org/licenses/by-nc/4.0/) which permits any noncommercial use, distribution, and reproduction in any medium, provided the original author(s) and the source are credited.
} 


\section{Preface}

In 2011, Jack E. Burkhalter, PhD, a psychologist and behavioral sciences researcher at Memorial Sloan Kettering Cancer Center (MSKCC) and Liz Margolies, LCSW, Executive Director of the National LGBT Cancer Network, began planning what would become the 2014 Summit on Cancer in the lesbians, gay men, bisexuals, and transgender (LGBT) Communities. Fueling the Summit concept was a desire to accelerate the progress in identifying and addressing the LGBT communities' cancer concerns and needs and to provide further catalyst for action among those most engaged in this area. To our knowledge, the Summit would be the first meeting of subject matter experts in LGBT cancer research, clinical care, healthcare policy, and survivorship and would include LGBT cancer survivors and advocates for LGBT health equity, speaking across disciplines and experience. The Summit would result in a plan of national scope focused on the dynamic intersection of cancer and LGBT communities. Burkhalter and Margolies spent the next year seeking funding to launch the planning process.

In early 2012, independent of the Summit planning efforts, MSKCC's Nursing Department and Callen-Lorde Community Health Center's (Callen-Lorde) Community Health Education unit had begun collaborating to address the gaps in knowledge regarding LGBT health concerns among healthcare professionals. Burkhalter and Margolies recognized that there would be much to gain in collaboration. A Summit planning committee was established and met monthly in person and by conference call. New planning committee members included Asa Radix, MD (Callen-Lorde), Hrafn Oli Sigurdsson, PhD, NP, PMHNP-BC (MSKCC), David Rice, RN, PhD (MSKCC, now at City of Hope), Jonathan Walland, LLB (MSKCC), Nelson F. Sanchez, MD (MSKCC), and Francisco O. Buchting, PhD (Buchting Consulting).

The planning committee articulated a primary goal for the historic convening: the collaborative creation of a National LGBT Cancer Action Plan, endorsed by all in attendance and to be disseminated widely through publication in a national journal, conferences, and social media. A secondary objective was to provide a forum for participants to network and plan future collaborations. When completed, the Action Plan would outline cancer disparities experienced by LGBT communities across the care continuum, recommend which steps were needed to catalyze progress in addressing cancer within the LGBT communities, and provide a blueprint for funding, research, and programming. The planning committee decided on a 2-day, in-person meeting with about 60 invited participants representative of the diverse identities and experiences within the LGBT communities. Participants would share lessons learned and identify gaps and remedies across the cancer care continuum from prevention to survivorship.

Summit activities were deliberated through an iterative process over the course of months until consensus was achieved on the final methods. The planning committee secured funding from multiple sources over the course of the next year. To ensure diverse participation, over $\$ 13,000$ in scholarship funding was distributed to 15 Summit participants.

\section{Introduction}

\section{LGBT communities and intersectionality}

$\mathbf{T}$ he term "LGBT" encompasses a broad community of persons who self-identify with one or more of the four populations within the LGBT community that include sexual orientation and gender identity minorities (due to space limitations, see the Institute of Medicine [IOM] Report glossary for definitions). ${ }^{1}$ When discussing the assessment of LGBT identities in data collection, we use the acronym SOGI to denote sexual orientation and comprehensive gender identities that include transgender persons. ${ }^{1,2}$ As is true for almost all U.S. minority populations, there is great diversity among the LGBT community members. In fact, the IOM report emphasizes that each LGBT population is distinct and, although the umbrella term is useful for capturing the commonly shared experiences of stigma and discrimination, each population has its own unique set of health and cancer risk factors and disparities. ${ }^{1}$ Thus, it is important to acknowledge that broad observations about "the LGBT community" may obscure differences among these populations, and it behooves researchers, policy experts, clinicians, and advocates to consider this in their work.

Barriers to understanding the diversity of LGBT communities and their state of health include a lack of demographic data collection in the U.S. Census, which does not capture SOGI information. Estimates for the size of LGBT communities vary, but methodologically strong studies suggest a range of $3.4 \%-3.8 \%$ of the population. ${ }^{3,4}$ A 2012 Gallup poll of a large national sample found that greater proportions of African Americans, Hispanics, and Asians identified as LGBT than was found for non-Hispanic whites. ${ }^{4}$ Women were more likely to identify as LGBT than were men $3.6 \%$ of women vs. $3.3 \%$ of men). Despite media stereotypes of wealthy, white, LGBT individuals, the same Gallup poll found that $35 \%$ of those who identified as LGBT reported incomes of less than $\$ 24,000$ a year versus $24 \%$ of the general population. ${ }^{4}$

These findings are consistent with other research showing that LGBT people are at a higher risk of poverty than the general population. ${ }^{5}$ LGBT persons may differ markedly in their life experiences by membership in different age cohorts, given the advances in social acceptance and legal rights for LGBT persons in the United States in the last decades and the impact and evolution of the acquired immunodeficiency syndrome (AIDS) epidemic since the early 1980's. These findings and observations argue for a nuanced approach to conceptualizing cancer concerns for a diverse LGBT community.

The inclusion of intersectionality in addressing cancer in the LGBT community emphasizes that the LGBT community is diverse on many levels, across SOGI categories, and this diversity may influence individuals' cancer risks, screening behaviors, and treatment and survivorship experiences. Intersectionality is a feminist sociological theory created by Kimberlé Williams Crenshaw ${ }^{6}$ that considers the intersection of marginalized or minority identities. Intersectionality also identifies the ways in which multiple oppressions coexist and interact on various and often simultaneous levels.

The multiple intersecting identities we considered included, but were not limited to race, ethnicity, age, class, gender identity, sexual orientation, and disability/ability. This diversity may influence an individual's cancer risks, screening behaviors, treatment, and survivorship experiences. The experiences 
of a blind African-American lesbian should take into consideration the ways each of these descriptors (disability/ability, race, and sexual orientation) interact and affect each other in social, legal, and policy environments, taking into account specific stigmas, stereotypes, and social and institutional discriminations. For example, a study of screening rates for colorectal and prostate cancers among men in California found that, overall, gay and bisexual men had equivalent prostate cancer screening rates compared with their heterosexual peers; however, African-American gay/bisexual men had significantly lower prostate cancer screening rates compared with African-American heterosexual men. ${ }^{7}$ Appreciating intersectionality will enhance our understanding of cancer prevention, care, and survivorship among the many constituents in LGBT communities.

The Action Plan presented herein calls for increased research into cancer prevention, treatment, and survivorship for LGBT communities. It is important that such research examines race, ethnicity, class, disability/ability, immigration status, and other sociodemographic factors. Addressing intersectionality mitigates the risk of further marginalizing those whose experiences exist at the intersection of multiple identities.

\section{Current state of knowledge about cancer in LGBT communities}

Cancer is a major health problem that affects the wellbeing and survival of the U.S. population. One in four deaths in the United States is due to cancer, and the lifetime probability of being diagnosed with an invasive cancer is $44 \%$ for men and $38 \%$ for women. ${ }^{6,8}$ Because of the rapidly aging population, cancer incidence is expected to rise by $45 \%$ to 2.3 million new diagnoses per year by 2030 . Approximately $75 \%$ of U.S. cancer deaths are linked to potentially avoidable lifestyle and environmental factors ${ }^{9}$; thus, emphasis has been placed on primary prevention and early detection of cancer. U.S. federal and nonfederal agencies acknowledge the existence of cancer disparities related to gender, age, race, ethnic origin, income, social class, disability/ability, and geographic location, but little focus and money have been devoted to assessing and understanding differences in the cancer burden associated with sexual orientation and gender identity.

The measurement of cancer incidence, morbidity, mortality, and survival is referred to as cancer surveillance. According to the National Cancer Institute (NCI), cancer surveillance also includes the assessment of environmental and behavioral cancer risk factors, screening practices, and the quality of care across the cancer care continuum. ${ }^{10}$ Surveillance is the major tool used to determine where healthcare disparities exist in cancer care and whether efforts to reduce the cancer burden in a given population are successful. To date, SOGI data are not collected by most cancer surveillance programs at the state and federal levels, resulting in a gross disadvantage to LGBT communities. When LGBT cancer experiences go unrecognized, it hinders research funding for cancer prevention and control interventions and impedes the efforts of healthcare providers, community advocates, researchers, policy makers, and state, federal, and other entities to address LGBT disparities.

An increasing number of published studies have emerged that document the cancer burden and experiences of LGBT communities across the cancer care continuum, including a recent review article. ${ }^{11}$ There are consistent findings of LGBT populations with higher rates of cancer risk behaviors, such as tobacco use ${ }^{12}$; yet, in the absence of cancer registry data, cancer incidence and mortality cannot be accurately determined. Ecological studies suggest the likelihood of greater cancer incidence and cancer mortality, ${ }^{13-16}$ and a study of the California population showed a difference in cancer prevalence, in that compared to heterosexual men, a cancer history is more common among gay men and they receive their diagnosis at a younger age. ${ }^{17}$ Finally, in 2015 , the first ever comprehensive look at cancer and LGBT populations was published that summarizes what is known about LGBT persons across the cancer continuum, including the outcomes of survivors, with the richest information focusing on breast and prostate cancer survivorship. ${ }^{18}$

\section{Legislative and regulatory background for cancer in LGBT communities}

In this section, we will highlight relevant legislation, regulatory, and other public health limitations and opportunities.

In contrast to most industrialized countries, the United States does not have national antidiscrimination protections for LGBT communities as they engage across the healthcare system. As a result, care may be affected at every step of the cancer care continuum beginning with access to care. While some individual states have enacted laws to prohibit discrimination in places of public accommodation, including hospitals and medical clinics, only a patchwork of limited protections exists at the federal level. For example, discrimination on the basis of sex or gender is prohibited under Title VII of the Civil Rights Act of 1964, Title IX of the Education Amendments of 1972, and Section 1557 of the Patient Protection and Affordable Care Act (PPACA). Novel legal arguments have also succeeded in finding protections for some LGBT patients under Section 504 of the Rehabilitation Act of 1973 and the Americans with Disabilities Act of 1990.

One notable development in recent years is the use of Medicare Conditions of Participation (42 CFR 482.24) as a mechanism to promote protections for LGBT patients. Since the vast majority of U.S. hospitals accept assignment from the Centers for Medicare and Medicaid Services (CMS), they are required to comply with the Conditions or risk the loss of reimbursement funding. On November 19, 2010, the CMS published a final rule codifying rights to hospital visitation and access for same-sex partners and their children and prohibiting limits on visitation on the basis of sex, gender identity, or sexual orientation.

On November 8, 2011, The Joint Commission, which accredits and certifies more than 20,500 healthcare organizations in the United States, released its Field Guide on LGBT Patient-Centered Care, ${ }^{2}$ which emphasized equal treatment of LGBT patients as a requirement for competent medical care. In 2011, new and revised standards designed to promote patient-centered communication were published in the Joint Commission's Comprehensive Accreditation Manual for Hospitals. ${ }^{19}$ The patient-centered communication standards include revised elements of performance that prohibit discrimination based on sexual orientation, gender identity, and gender expression and ensure access to a support person of the patient's choice, which are critical issues 
to the LGBT community. These milestones are especially noteworthy due to The Joint Commission's unmatched influence in setting policy standards and conducting field compliance audits in virtually every U.S. hospital.

On June 29, 2011, the U.S. Department of Health and Human Services (HHS) announced an LGBT national data progression plan based on the IOM's March 2011 report. ${ }^{1}$ Finally, Section 4302 of the PPACA mandates that research includes data points consisting of race, ethnicity, sex, primary language, and disability status, as well as "any other demographic data as deemed appropriate by the Secretary regarding health disparities (pp. 124.STAT.378-379)."20 This last clause authorized the HHS Secretary to take steps to increase SOGI data collection on health surveys and in electronic health records (EHRs).

\section{Summit Participants and Method}

In this section, we describe the participants and methods of organizing and conducting the Summit.

\section{Participants}

Key to Summit success was identification of a cadre of participants with the subject matter expertise, knowledge, and commitment to advancing the health and well-being of the LGBT communities through a focus on cancer, and who in collaboration would generate a comprehensive and balanced assessment. The planning committee identified individuals in four key activity areas: (1) cancer research; (2) clinical cancer care; (3) policy; and (4) advocacy for cancer survivorship and LGBT health equity. In developing the list of summit invitees, we also considered geographical location, race and ethnicity, age, discipline, and LGBT subgroups. Any gaps in representation and diversity were addressed further, and the committee built financial assistance into the budget to eliminate economic barriers for invited participants to attend the meeting. Despite the committee's efforts, it remained challenging to identify people with expertise in both cancer and the bisexual or transgender communities. Of the 86 individuals invited, 59 (69\%) accepted the invitation, and of those accepting, a final 56 (65\% of those invited) attended the Summit. The list of participants can be found in the Supplementary Appendix (Supplementary Material is available online at www.liebertpub.com/lgbt). Participants were $29 \%$ racial/ethnic minorities, $39 \%$ were lesbian or bisexual women, $39 \%$ were gay or bisexual men, and $22 \%$ identified as transgender. The four activity levels were well represented by the participants, with $34 \%$ each in research and cancer care, $15 \%$ in survivorship and community activism, and $17 \%$ in policy.

\section{Summit process}

A 1.5-day event was convened at MSKCC's Manhattan medical campus on January 16-17, 2014. On the first day of the Summit, multiple, structured small-group discussions were organized to identify cancer gaps and related needs for LGBT communities, and these discussions were facilitated to promote the inclusion of diverse perspectives. Before the first day, participants had been assigned to each of the consecutive breakout sessions on three topics (Table 1) aligned with their individual experience and knowledge. This format had the participants joining three small groups over the course of the day, which permitted the inclusion of multiple perspectives and ensured that all aspects of the cancer continuum were addressed on a variety of levels.

Templates were designed for each group to record their ideas, with separate columns for describing gaps, rationale, actions, and anticipated outcomes for each suggested action (Fig. 1). During the breakout session, participants were divided into four groups (i.e., researchers, care providers, survivors/advocates, and policy experts). Each group filled out the template form during an open moderated discussion. Forms were completed during Stakeholders, Cancer Care Continuum, and LGBT subpopulation sessions over the course of Day 1.

Each group had 90 minutes to complete their work, with a facilitator and a scribe to record discussion items on the activity template forms. Repetition of items or themes throughout the day was expected and seen as an indicator of salience and importance to participants.

In addition to the small-group breakout sessions, a wholegroup process was also needed to secure consensus on the final action items to be included in the plan. By the end of the first day, 11 activity sheets had been completed, with a range of 9 (policy) to 28 items (survivors/advocates) and a median of 20 items generated per activity sheet.

On the morning of the Summit's second day, a plenary session was held. Facilitated by Scout, PhD, of LGBT HealthLink, the day began with presentations from discussion facilitators of each breakout session followed by a facilitated whole-group discussion that created consensus on the key action items to be included in the National LGBT Cancer Action Plan. The synthesis of ideas and recommendations generated from the Summit is presented in the next section.

\section{Summit Recommendations}

\section{SOGI data collection and research on LGBT communities and cancer}

The lack of ongoing and standardized assessment of SOGI in healthcare settings and in federal, state, and local health surveys means that the state of knowledge about the prevalence and incidence of cancer in the LGBT communities, as well as cancer concerns, needs, and health outcomes, is markedly deficient. ${ }^{2,3}$ Policymakers, researchers, healthcare providers, and community advocates need data on the health of LGBT persons and communities to identify cancer and other health disparities and take action to remedy them.

Omitting the assessment of SOGI from cancer surveillance and research creates a "catch 22 " status. Implementation of effective healthcare policy to address cancer-related disparities is delayed because of the lack of adequate LGBT-inclusive surveillance and research data. The excuse for inaction becomes circular since surveillance and research drive the creation of policy, which in turn drives resources and mandates for population-targeted prevention and healthcare as well as additional surveillance and research inclusion. Thus, cancer surveillance not inclusive of SOGI data justifies inaction in addressing likely disparities and creating policies that lead to culturally competent services and healthcare for LGBT communities.

National data collection efforts. Diverse healthcare stakeholders rely on data concerning the health of LGBT communities. Historically, major federal health surveys have not 
Table 1. Organization of Summit Activities by Session Themes and Content Groups

Sessions

1. Stakeholders

2. Cancer care continuum

3. LGBT subpopulations

$\begin{array}{ll}\text { Researchers } & \text { Care providers } \\ \text { Prevention } & \text { Screening }\end{array}$

Lesbian/bisexual women

Breakout groups by content

Survivors/advocates

Diagnosis/treatment

Gay/bisexual men
Policy experts

Survivorship/palliative and end-of-life care Transgender persons

LGBT, lesbians, gay men, bisexuals, and transgender.

routinely collected SOGI data, making it difficult to collect nationally representative data on LGBT communities. As noted earlier, the PPACA requires HHS, through its programs and surveys, to collect a range of demographic data related to understanding health disparities. As part of implementing this provision, HHS has instituted an "LGBT Data Progression Plan" to add SOGI questions to federal population health surveys. In 2013, a sexual orientation question was added to the National Health Interview Survey, which is the federal government's flagship health survey, and work is underway to test and implement gender identity questions. ${ }^{21}$

SEER cancer registry. The preeminent source of information on cancer incidence, mortality, and survival in the United States is the Surveillance, Epidemiology, and End Results (SEER) Program of the NCI. ${ }^{22}$ SEER data are used extensively by researchers, clinicians, public health officials, legislators, policymakers, community groups, and the public. SEER collects and publishes cancer incidence, mortality, and survival data from population-based cancer registries that include $\sim 28 \%$ of the U.S. population. ${ }^{22}$ SEER Program registries collect data from 18 geographic areas across the United States, including 10 state registries, five metropolitan area registries, and three Native American registries. SEER data cover $26 \%$ of African Americans, $38 \%$ of Hispanics, $44 \%$ of American Indians and Alaska Natives, $50 \%$ of Asians, and $67 \%$ of Hawaiian/Pacific Islanders.

These data on specific subpopulations within the United States inform cancer prevention and control policies and activities as they can provide a rationale for targeting cancer disparities observed within and between the subpopulations. ${ }^{22}$ The SEER Program registries routinely collect data on patient

\begin{tabular}{|c|}
\hline $\begin{array}{c}\text { 1. STAKEHOLDER GROUPS } \\
\text { Researchers -- Care Providers - Survivors/Advocates - Policy Experts } \\
\text { Day 1, Session 1 Summary Sheet }\end{array}$ \\
\hline
\end{tabular}

This sheet will help each Session's participants organize the gaps, needs, actions, and outcomes into one table.

- Gap is "what's missing?" from the existing cancer knowledge, infrastructure and systems, and activities and programs for LGBT persons. Ex: No population-level U.S. data exist on prevalence of cancer by sexual orientation and gender identity (SO/GI).

- Rationale is "why is it important to address the gap?" Ex: Population-level data on cancer prevalence for LGBT persons are needed because without it, programs targeted to them are less likely to be developed and if they were, they would lack data that can activate community members to take action.

- Actions are "what should be done to bridge the gap?" The gap and rationale compel action. Ex: Work with state, federal and cancer registry officials in including SO/GI questions in cancer registries.

- Outcomes are the expected results for the action(s) taken. It answers the question "How will we know that the action is effective in addressing the gap?" Ex: The inclusion of $\mathrm{SO} / \mathrm{Gl}$ questions in cancer registries, enabling analysis of cancer data by SO/GI. Issues of measurement of outcomes can be addressed as well.

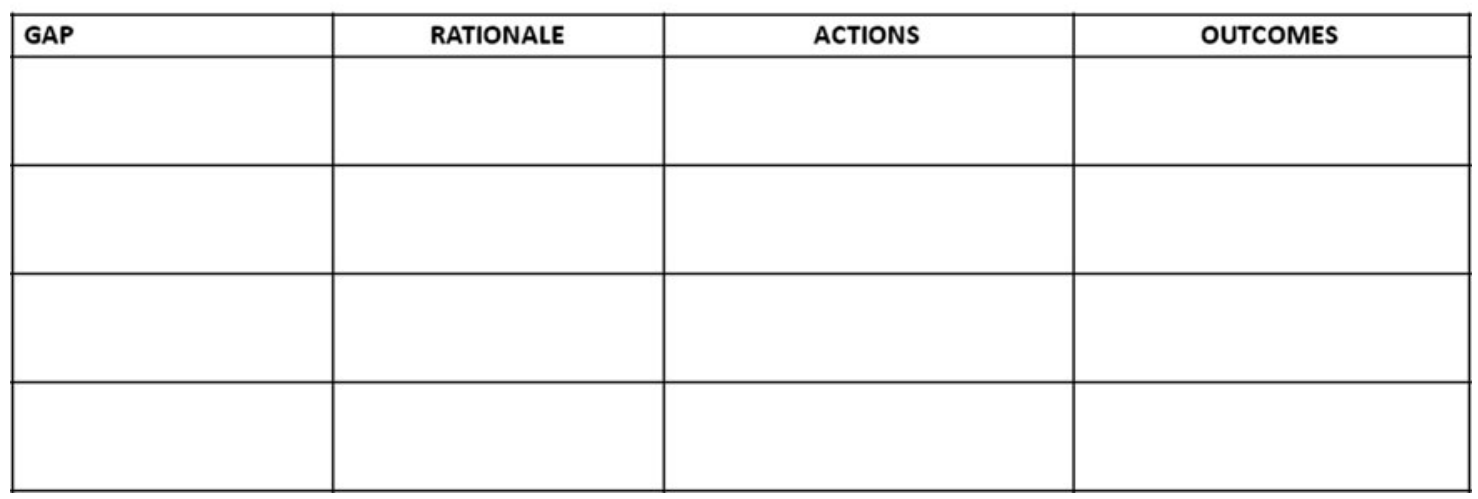

FIG. 1. Example of the breakout session template sheet for stakeholder groups. 
demographics, primary tumor site, tumor morphology and stage at diagnosis, first course of treatment, and follow-up for vital status. Patient demographics do not include SOGI data collection. The population data used in calculating cancer rates are obtained periodically from the Census Bureau, which itself does not routinely collect SOGI data, but has collected data on same-sex households. ${ }^{23}$ SEER data are updated annually and are available to the public. SEER tracks the intersection of race/ethnicity, sex, and age and the prevalence of various kinds of cancer, and SEER reports on its website about the intersection of socioeconomic status, age, and race/ethnicity and cancers. The SEER 2014 Annual Report to the Nation on the Status of Cancer depicts racial/ethnic, sex, and age differences, but it does not address cancer disparities affecting LGBT people. ${ }^{24}$

Electronic health records. Collecting data on SOGI in healthcare settings and EHRs is essential to better understanding the incidence and treatment outcomes of cancer among LGBT communities. For example, without assessing SOGI, it is not possible to assess whether lesbian and bisexual women are receiving the same quality of care that other women are experiencing or whether disparities in preventive care such as lower rates of cervical and breast cancer screenings are being addressed. Knowledge of a patient's gender identity is essential to understanding a patient's history and clinical care needs. For example, transgender men should be offered cervical cancer screening, and prostate cancer screening should be discussed with transgender women 50 years and older, but few providers know of these needs or how to offer them in a culturally sensitive way. ${ }^{25}$

The federal government is currently considering steps that would support healthcare providers' inclusion of SOGI data collection in clinical settings. One opportunity is provided by the nation's shift from paper to EHRs. "Meaningful use" of EHRs involves using certified EHR technology to insure that appropriate demographic and clinical elements are included in EHRs that will allow the measurement of quality and reduce disparities. It is hoped that meaningful use of EHRs will result in improved clinical outcomes, improved population health, and better research on health systems. ${ }^{26}$ Meaningful use of EHRs has been shown to improve diabetes care and outcomes. ${ }^{27}$ CMS and the Office of the National Coordinator for Health Information Technology are considering requiring certified EHRs under the Meaningful Use incentive program to have functionality to track SOGI data collection. $^{28}$ In an April 2014 public comment, The Fenway Institute, the Center for American Progress, and more than 150 healthcare organizations recommended SOGI questions for use in EHRs that had been field tested in four health centers in different regions of the country and found effective. ${ }^{28}$

Risk behavior surveys. The Behavioral Risk Factor Surveillance System (BRFSS), funded by the Centers for Disease Control and Prevention (CDC), is a nationwide and ongoing telephone health survey system that informs the nation about environmental and behavioral risk factors for cancer. ${ }^{29}$ SOGI questions are not part of the standardized core questionnaire that is used in every state. Only a limited number of states, Massachusetts among them, add SOGI questions to their survey. For example, in 2009, only 13 states and the District of Columbia included a sexual orienta- tion question on their BRFSS. ${ }^{30}$ States that have asked about sexual orientation have documented disparities and used the data to inform public health programming to address them. Arizona's public health department found through its BRFSS that $31 \%$ of Arizona lesbians smoked, about twice the rate of the state's general female population. As a result, Tobacco Free Arizona targets lesbians and other members of the LGBT communities with prevention and cessation interventions. ${ }^{30}$ New Mexico, Washington state, and Massachusetts also documented tobacco use disparities affecting lesbian, gay, and bisexual people, and targeted the LGBT communities with tobacco prevention and cessation efforts. ${ }^{30}$

The repercussions of this practice are that each year, few LGBT persons are identifiable among the BRFSS respondents leaving us without reliable and consistent information about LGBT trends in cancer risks and screening behaviors. Moreover, the small numbers of LGBT persons that are identifiable in their respective states make further analyses of differences in these behaviors by age, race/ethnicity, location, or other characteristic mostly impossible.

BRFSS should add SOGI questions to its core questionnaire, and state policymakers can take the initiative and add SOGI questions to their state BRFSS at minimal cost and with significant benefit for understanding cancer risk behaviors among LGBT communities of that state. The 2014 Fenway Institute brief suggests wording for sexual orientation and behavior questions and approaches to data analysis. ${ }^{30}$

The Youth Risk Behavior Survey (YRBS) is also conducted in all 50 states. Sexual orientation questions (identity and behavior) are optional, and about 17 states asked about sexual orientation in 2013. Only one-Massachusetts_-asked a transgender status question. However, in early 2014, the CDC indicated that sexual orientation questions would be included in the 2015 core questionnaire for YRBS. This will increase the likelihood that states will ask the questions and document sexual minority health-risk behaviors that are related to cancer, such as tobacco use. We urge all states to ask about SOGI on their YRBSs.

Other health surveys. According to the NIH LGBT Research Coordinating Committee, ${ }^{31}$ a number of national health surveys have asked about sexual orientation for many years, including the General Social Survey, National Epidemiologic Survey on Alcohol and Related Conditions, the National Health and Nutrition Examination Survey, and the National Survey of Family Growth. The National Health Interview Survey, which collects data on insurance coverage, asked about sexual orientation for the first time in 2013. The Substance Abuse and Mental Health Services Administration's National Survey on Drug Use and Health is considering adding sexual orientation questions. We strongly urge that all national health surveys add sexual orientation questions (both identity and behavior) and gender identity questions to better understand behavioral risk factors that influence cancer within LGBT communities.

NIH funding. U.S. federally supported funding for LGBTspecific health research outside the context of human immunodeficiency virus (HIV) disease and other sexually transmitted diseases has been limited. The Summit participants identified three areas of particular need. First, it is important to organize stakeholders and promote education within the NIH and its institutes, centers, and offices, and in particular the NCI, about 
the health and cancer needs of LGBT communities to arm with facts and sensitize decision-makers who help set scientific and funding priorities. Second, there is a gap in financial support of research to develop and test cancer prevention and control interventions targeted and tailored to LGBT communities. Third, to increase the number of qualified LGBT researchers, the NIH should implement ways to assure that career development and training grants include those conducting high-quality LGBT cancer research.

Pertinent to these three cancer-focused areas of need is a 2013 report from the NIH LGBT Research Coordinating Committee (RCC) that examined the gaps and areas of opportunity for NIH to consider in the wake of the 2011 IOM report on LGBT Health. ${ }^{1,31}$ Using $2010 \mathrm{NIH}$ data in mapping the NIH portfolio to the IOM report's list of recommendations, the RCC found that the largest percentages of NIHfunded LGBT projects classified by research condition and disease categories were in behavioral and social sciences (82\%), HIV/AIDS (81.5\%), mental health (46.4\%), and substance abuse $(30.2 \%)$. Projects on cancer constituted only $7.7 \%$ of projects. Note that projects could be classified across multiple categories; hence, the total exceeds $100 \%$. Aligned with these percentages are further data on the distribution of LGBT projects across NIH institutes, centers, or offices (ICOs). Together, the National Institute of Mental Health (NIMH) and the National Institute on Drug Abuse account for over $50 \%$ of LGBT-related projects and 11 other ICOs accounted for the remainder, with the NCI accounting for only $5.2 \%$ of LGBT projects.

The RCC identified a number of research opportunities, including research to better understand differential risks and rates of cancers such as cervical cancer, breast cancer, anal cancer, Kaposi's sarcoma, and possibly lung cancer, and other types of cancer among LGBT persons (p. 10). ${ }^{31}$ In addition, the RCC report recognized that training, career development in research, and cultural competency in working with LGBT populations are key elements to advancing the NIH research portfolio in LGBT health and ultimately to improve the health outcomes in LGBT persons (pp. 1314). ${ }^{31}$ This echoes the Summit's fourth recommendation and adds LGBT cultural competency training to the extant gaps.

\section{Recommendations}

1. Add SOGI questions to all national health surveys and promote SOGI data collection in diverse healthcare settings so as to better understand psychosocial, behavioral, and medical risk factors that can increase LGBT persons' cancer risk and to examine health outcomes and disparities in each LGBT community.

2. Organize stakeholders and promote education within the $\mathrm{NIH}$ and its institutes, centers, and offices, and in particular the NCI, about the health and cancer needs of LGBT communities to arm with facts and sensitize decisionmakers who help set scientific and funding priorities.

3. Overcome the gap in financial support of research to develop and test cancer prevention and control interventions targeted and tailored to LGBT communities by issuing research funding opportunities specific to the population.

4. Increase the amount of federal funding dedicated to LGBT cancer research. Furthermore, assure that career development and training grants for under-represented populations in the workforce include those identifying as LGBT and with potential for conducting high-quality cancer research with LGBT communities. ${ }^{\mathrm{i}}$

5. Address the absence of SEER cancer registry data on SOGI. SEER should consider partnering with cancer researchers to pilot test such an effort, perhaps within a region or state, to identify and overcome barriers to standard collection of SOGI data.

6. Recognize intersectionality within the LGBT communities when conducting cancer research by assessing and examining the impact of SOGI, race, ethnicity, class, disability/ability, and other sociodemographic factors on cancer outcomes across the cancer care continuum.

\section{Clinical care of LGBT patients}

Cancer epidemiology in the LGBT population. Despite limited data due to the exclusion of SOGI assessment from large population-based datasets, some disparities in cancer epidemiology have been identified in LGBT communities compared to other groups. ${ }^{32,33}$ For example, rates of breast, lung, and colorectal cancers appear to differ for lesbians compared to heterosexual women. ${ }^{34}$ Potential explanations for elevated cancer risks for lesbians are population differences in parity, smoking status, cancer screening, and access to care. Rates of smoking are higher in LGBT communities compared to other populations, ${ }^{32,35}$ which may increase the risk for 12 cancers caused by tobacco use. ${ }^{36}$ Disparities in screening behaviors in LGBT communities have also been identified and need to be more fully addressed in future efforts. ${ }^{37,38}$ For example, lesbians and bisexual women experience cervical cancer at the same rate as heterosexual women, but are much less likely to get routine cervical screening. ${ }^{39,40}$

Support services and caregiver networks. Within the context of quality of life, social, psychological, and sexual health outcomes of cancer care among LGBT communities need to be carefully considered and addressed. These include the concerns of LGBT patients and couples, their families, and other caregivers. Treatment for a variety of cancers can have a significant impact on body image and sexual function. $^{41,42}$ To date, there has been a relative paucity of research and education on this topic specific to the LGBT communities, although some new data are beginning to emerge. ${ }^{43-47}$

Caregiver needs, resources, and other support services specific to LGBT cancer patients have not been particularly well defined to date, although there are some data on this topic. ${ }^{48-50}$ In part, this may be due to presumption of a heteronormative cultural paradigm surrounding caregiving and support for cancer patients. ${ }^{51,52}$ However, there is an

\footnotetext{
${ }^{\mathrm{i}}$ Although we can find no data to support the goal of increasing the number of LGBT-identified persons in the research workforce, this is likely due to non-inclusion of SOGI questions in sociodemographic data collection with trainees. Given the history of LGBT persons as marginalized minorities and the perceived and real harms of being open in one's sexual orientation or gender identity, "out" role models in academic research settings are likely to be few or concentrated mainly in large urban areas. We believe that adding LGBT persons as an under-represented group is consistent with the NIH program on Enhancing the Diversity of the NIH-Funded Workforce (http://commonfund.nih.gov/diversity/overview).
} 
historical wealth of information related to the provision of care within the LGBT population related to the HIV epidemic that could, at least in part, be used as a model for future work. Caregivers often have a sense of isolation and access to culturally competent support services could be quite valuable. ${ }^{53}$ Development and implementation of buddy programs linking LGBT cancer patients and caregivers with cancer survivors and advocates could provide a great benefit. While there are many support groups for cancer patients, relatively few focus specifically on the needs of LGBT communities, and fear of substandard care or nonwelcoming interactions has been documented. ${ }^{48}$ Such resources could be developed and linked to existing programs, including live or virtual support groups; local, regional, or national support programs; online or telephone-based resources; or other models.

Care coordination. Direct services for cancer care are provided in a wide variety of settings. Most are organized at a local or regional level, often coordinated through a specific provider hospital or clinic. Although many excellent programs exist, few are focused specifically on the needs of LGBT communities. Expanded organizational networking is needed to help address this gap. This should include efforts for cancer diagnosis and treatment, as well as preventive care and wellness. Quality of life should be a key focal point, meaning that efforts need to move beyond just identifying healthcare disparities in LGBT communities to also embrace improving health and well-being. Programming could benefit from integration with diverse LGBT-focused resources available both locally and nationally. In particular, the development and dissemination of resources in rural areas and communities with less LGBT visibility are important. The Ryan White HIV/AIDS Program, which has been so successful in the provision of HIV clinical care resources, could serve as a model for similar programming nationally for cancer care in the LGBT communities.

Comorbidity. Cancer care must be considered within the framework of underlying comorbidities and other health concerns. The incidence and prevalence of many chronic conditions increase with aging and these have important clinical implications. For example, as the treatment and prognosis for HIV infection and AIDS have improved, more HIVinfected people are living longer. Aging increases cancer risks, and persons living with HIV, who include disproportionately high numbers of gay and bisexual men, are at higher risk for many cancers compared with the general population. ${ }^{54}$ Other common comorbidities include diabetes, hypertension, arthritis, and pulmonary and cardiovascular diseases. Overweight and obesity are also important comorbid conditions that can influence cancer epidemiology in LGBT communities. ${ }^{55}$ Thus, future research on health disparities in LGBT communities for these various conditions will be important.

Palliative and end-of-life care. Provision of high-quality healthcare at the end of life is a critically important component of clinical cancer care. LGBT communities have unique needs to be considered and addressed in this phase of care. ${ }^{4,56,57}$ Many LGBT people want to retain their SOGI identity and remain "out" at this stage of their life and need care services that will support their full identity without stigma, bias, or discrimination. ${ }^{58}$ Advance directives, designated power of attor- ney for healthcare decision-making, and other legal issues need to be carefully considered. Legal requirements may differ based on the location and jurisdiction where LGBT people live. National access to legal marriage may resolve some of the issues for some same-sex couples and their dependent children. Providers should receive enhanced education about resources addressing LGBT healthcare and other legal needs. Finally, in this phase of cancer care, LGBT persons and their loved ones need grief and bereavement services that are inclusive and welcoming.

Insurance, coding, and reimbursement issues. The structure of healthcare financing in the United States is complex and dynamic. Data show that there is a substantial disparity for health insurance and clinical coverage among LGBT communities compared to other population groups. ${ }^{59}$ Before the expansion of health insurance coverage in 2013-2014, surveys showed much lower rates of insurance coverage for same-sex couples, ${ }^{60}$ LGB individuals, ${ }^{61}$ and transgender individuals, especially African-American transgender persons. ${ }^{62}$ In addition, transgender individuals experience limitations in coverage for transition-related care and cancer screening when anatomy is incongruent with the sex listed in the coverage. Parts of the PPACA may help to alleviate some of these health insurance problems, but there is ongoing debate and legislative maneuvering regarding this law. ${ }^{63}$ Even within the coding and billing structure, there have been inequities identified, particularly related to gender identity. Efforts to address and improve this are being incorporated into many EHRs and other systems. The adoption of ICD-10, which is designed, in part, to expand specificity, may also help in this regard.

\section{Recommendations}

1. Increase research to document elevated cancer risks and cancer screening disparities in LGBT communities.

2. Develop psychosocial and educational support groups specifically for LGBT survivors and caregivers, and when this is not feasible, assure the cultural competence of professional support service providers to better meet the needs of LGBT communities.

3. Improve care coordination for LGBT patients, survivors, and caregivers through the integration of LGBT community resources. These resources include culturally competent oncologists, primary care and specialty physicians, mental health providers, and other professional providers.

4. Educate healthcare providers about the unique cooccurring conditions that LGBT cancer patients may present in their care settings.

5. Ensure that palliative and end-of-life care addresses the specific legal and psychosocial needs of LGBT communities.

6. Support efforts to increase insurance coverage for LGBT communities, with a focus on the transition and cancer care needs of transgender communities.

\section{Education and training of healthcare providers}

Education and training. The 2011 IOM report highlighted multiple healthcare disparities encountered by LGBT communities, including healthcare discrimination and the 
lack of providers who are adequately trained in LGBT health. ${ }^{1}$ Discriminatory attitudes and behavior have been described in diverse healthcare settings, among medical, nursing, and mental health providers, as well as among health profession students, ${ }^{62,64-66}$ which can result in LGBT individuals perceiving and experiencing discrimination. ${ }^{64,67,68}$ Stigma and discrimination may be among the causes for the low uptake of preventive health services, for example, colon cancer screenings by transgender persons ${ }^{62}$ and cervical cancer screenings by lesbians. ${ }^{67,69}$ In addition to overt discrimination, such as denial of care, verbal and physical assault faced by LGBT patients, more subtle forms of discrimination exist. These include assumed heterosexism (prejudice or discrimination based on the assumption that heterosexuality, but not bi- or homosexuality, is normal) and transphobia (intense dislike or prejudice toward transgender persons), when providers may not appropriately ask their patients about their gender identity and sexual orientation. ${ }^{70}$

Healthcare providers often do not receive adequate training about LGBT health. A survey of medical schools in the United States and Canada revealed that the median time spent covering LGBT issues was 5 hours, with quality and content varying significantly, and little to no coverage of transgender-related health issues. ${ }^{71}$ Nearly $7 \%$ of schools had no LGBT content whatsoever. Similar findings regarding the lack of LGBT curricular content have been observed in postgraduate trainees, ${ }^{72}$ mental health providers, $^{73}$ and among dental and public health students. ${ }^{74,75}$

LGBT health curricula. Several agencies and professional societies, such as GLMA: Health Professionals Advancing LGBT Equality (formerly the Gay and Lesbian Medical Association), the Association of American Medical Colleges, and the American Nurses Association, among others, have called for healthcare providers to receive training specific to LGBT health with the goal of raising awareness about the unique health concerns and barriers to care faced by these populations. ${ }^{2,76,77}$ Since the publication of these reports, as well as articles demonstrating the dearth of LGBT training in health professions schools, several universities have attempted to improve their curricula. Many have shown that these curriculum interventions increased knowledge of LGBT health concerns ${ }^{78,79}$ as well as improved attitudes toward LGBT patients. ${ }^{80,81}$ The published trainings have had different formats, including case-based training, webinars, and didactic lectures and panels. Integrating LGBT persons into the training as trainers or as panel participants has been highly successful at raising awareness of LGBT health concerns. ${ }^{82}$ Few of these educational interventions have specifically evaluated whether behavioral practice changes or patient health outcomes are improved; however, when agencies have received training, they are more likely to provide LGBT outreach and services, ${ }^{83}$ underscoring the need to implement LGBT training beyond the classroom and in all healthcare sectors and settings.

Agency standards. Several accrediting organizations and health profession agencies have offered guidance for the care of LGBT persons. In addition to the field guide published by The Joint Commission in $2011,{ }^{2}$ the National Standards for Culturally and Linguistically Appropriate Services in Health and Healthcare (the National CLAS Standards) were recently revised and are now inclusive of
LGBT individuals. ${ }^{76}$ Recently, the New York City Health and Hospitals Corporation (HHC), which operates the public hospitals and clinics in New York City, implemented mandatory LGBT cultural competency training of all their staff. ${ }^{84}$

Provider accreditation. Several health professions credentialing organizations have included LGBT health as a priority issue. These include the American Medical Association (policy H-295.878), the American Academy of Pediatrics, ${ }^{85}$ and the American College of Obstetricians and Gynecologists. ${ }^{86}$ In addition, The Fenway Institute, GLMA: Health Professionals Advancing LGBT Equality, and many other organizations offer formal training and educational opportunities focused on LGBT health.

Community education. LGBT persons are often aware of certain health disparities, for example, the higher rates of HIV and sexually transmitted infections among gay and bisexual men; however, this may not extend to other important health concerns for LGBT communities, for example, the increased risk for HPV-related anal cancer or the need for cervical cancer screening for transgender men and lesbians. ${ }^{67} \mathrm{~A}$ prime example was the low prioritization of tobacco as an LGBT issue among community leaders ${ }^{87}$ despite strong evidence that cigarette smoking is more prevalent among LGBT persons compared with the general population. ${ }^{88}$ Studies also find lower rates of knowledge about aging and end-of-life issues among LGBT communities, which is a particular concern in cancer treatment and care. ${ }^{56}$ In order for health education and prevention messages to target LGBT communities appropriately, they should include community members at all stages of implementation, from design to rollout and be inclusive of ethnic, racial, and age diversity.

\section{Recommendations}

1. Develop accreditation agency standards for the provision of culturally competent care to LGBT people and to assure professional training in LGBT cultural competence and health for providers of primary care, cancer screening and treatment, and cancer survivorship healthcare both during their academic training and for those already working in the field. This can be best accomplished by working with LGBT-focused organizations and other content experts in these areas.

2. Educate LGBT communities about their increased cancer risks and the importance of appropriate cancer screening and early detection through outreach by cancer experts through tailored lectures, print materials, internet content, mass media messaging, and other means that will effectively engage the community.

3. Increase representation of LGBT persons in leadership positions and throughout the workforce. The workforce pipeline draws from many streams, but for there to be greater LGBT representation at all levels of the cancer healthcare continuum and in health policy and research, efforts are needed to welcome, include, and develop the potential of LGBT persons within the under-represented populations in the workforce. This will entail collecting SOGI data to track the effectiveness of such efforts, as well as targeting for recruitment of LGBT-identified persons in academic and training programs and assuring 
that they will experience LGBT-affirmative environments and mentoring opportunities in their new settings.

4. Initiate a comprehensive effort to identify and modify healthcare organization policies that are not inclusive or pose barriers to patient-centered cancer care for LGBT persons. These policies may range from how to manage the comfort and confidentiality of transgender patients presenting for cancer screening based on genderspecific anatomy to providing culturally sensitive psychosocial support for LGBT cancer survivors. Systemic changes promoting equity in LGBT cancer care are more likely to be implemented when an independent prestigious organization advocates such changes and more so when mandated by an accrediting or certifying organization. Furthermore, by instituting collaborations with LGBT advocacy and professional groups, healthcare organizations can establish a lifeline when addressing internal LGBT-related policies, procedures, and patient concerns.

\section{Conclusions}

The 2014 National Summit on Cancer in the LGBT Communities comprising 56 individuals with diverse identities, experiences, and knowledge about LGBT communities and cancer addressed the spheres of cancer research, clinical cancer care, healthcare policy, and advocacy for cancer survivorship and LGBT health equity. They identified three overarching themes and produced 16 recommendations to advance the state of knowledge and action in this area. First, participants emphasized translation of the concept of intersectionality into research, policy, clinical care. and advocacy because of the diverse races, ethnicities, ages, disabilities/abilities, class, gender identities, and sexual orientations within LGBT communities. In state and federal health surveys, and most importantly in the SEER cancer registry, this white paper strongly recommended the consistent assessment of SOGI to understand the incidence of cancer within LGBT communities and identify cancer disparities. Furthermore, healthcare facilities should assess and capture SOGI in their EHRs. The NIH wields great influence in setting and funding the research agenda for the nation, and this article recommended education and focus within the NIH, and in particular the NCI, on LGBT communities' cancer concerns and promotion of research in this area by providing more funding opportunities that are focused on or inclusive of LGBT communities.

Many LGBT persons experience stigma and discrimination within the healthcare system, from being confronted with an assumption of heterosexuality to outright discrimination and abuse and from the point of cancer screening to care at the end of life. Healthcare agencies and providers should actively seek to provide patient and caregiver support services that are culturally competent, welcoming, and affirmative for LGBT cancer patients and their families. To this end, partnering with LGBT-affirmative and knowledgeable community resources was also recommended. LGBT persons have experienced disparities in health insurance coverage, and despite the passage of the PPACA and its goals of addressing health coverage for underserved populations, transgender persons still experience barriers to cancer screening and transition-related care. Recommendations were presented that address these concerns as well as cooccurring conditions that disproportionately affect LGBT communities, such as HIV and AIDS.

The Summit participants took up the issue of education of healthcare providers about LGBT health and cancer risk. It was recommended that primary, screening, treatment, and cancer survivorship healthcare providers receive training on LGBT health and, importantly, receive cultural competency training to assure good communication and engagement of LGBT persons in their care. The education of LGBT communities about their increased cancer risks was strongly recommended, with a focus on appropriate cancer screening and early detection. Finally, identifying policies and practices that are not inclusive of LGBT persons or present barriers to providing patient-centered care was recommended. LGBT advocacy and professional groups were cited as helpful collaborators in this effort.

Despite the strengths of the diverse and knowledgeable participants in the Summit and the range of topics addressed, limitations in the scope of recommendations presented are acknowledged. The Summit's focus did not include the specific cancer concerns of LGBT youth, those identifying as queer, questioning, or asexual, or those with somatic intersex conditions or who identify as intersex. Given the evolving terminology describing diverse identities within sexual and gender minorities, future efforts should examine cancer risks, incidence, and mortality in these populations as well. Although end-of-life care was discussed in the Summit, it was not proposed as a topic in breakout sessions; thus, this important aspect of cancer care needs greater focus in future such convenings. Finally, a consensus process that covers such broad and complex content areas as cancer and the cancer care continuum, their intersection with very diverse communities that LGBT persons comprise, and all within a relatively short time period of 1.5 days is unlikely to do full justice to the topic. With these limitations acknowledged, the authors propose that this first-time gathering represents an important step in raising awareness about the importance of cancer prevention and control for LGBT communities and hope that the proposed recommendations propel stakeholders to take timely and needed action.

\section{Acknowledgments}

We gratefully acknowledge funding support from the following organizations: LGBT HealthLink, The Palette Fund, Livestrong Foundation, MSKCC Geri and ME Fund, the MSKCC Survivorship Program, and support of the NCI MSK Cancer Center Support Grant/Core Grant P30 CA008748. The invited Summit participants provided the content of this white paper, and we acknowledge with gratitude their dedication to promoting LGBT health and the passion and expertise they provided regarding the LGBT communities and cancer. We thank Scout, PhD, who provided valuable consultation to the planning committee and facilitated the consensus-building activities of the Summit's second day. We also wish to acknowledge the work of Jenna McDavid and Michael G. Bare of the National LGBT Cancer Network and the assistance of Christopher S. Webster at MSKCC in administrative support for the Summit logistics. Finally, we acknowledge the work of Summit volunteers Kwame Badu-Danso, Stephen Jean, Kevin Kahn, Richard Remigio, and Vicki Wong. 


\section{Author Disclosure Statement}

No competing financial interests exist.

\section{References}

1. Institute of Medicine (US) Committee on Lesbian, Gay, Bisexual, and Transgender Health Issues and Research Gaps and Opportunities: The Health of Lesbian, Gay, Bisexual, and Transgender People: Building a Foundation for Better Understanding. Washington, DC: National Academies Press, 2011.

2. The Joint Commission: Advancing Effective Communication, Cultural Competence, and Patient- and Family-Centered Care for the Lesbian, Gay, Bisexual, and Transgender (LGBT) Community: A Field Guide. LGBTFieldGuide.pdf.: Oak Brook, IL: The Joint Commission, 2011.

3. Gates GJ: How Many People are Lesbian, Gay, Bisexual and Transgender? The Williams Institute on Sexual Orientation Law and Public Policy: UCLA School of Law. 2011. Available at http://williamsinstitute.law.ucla.edu/research/ census-lgbt-demographics-studies/how-many-people-arelesbian-gay-bisexual-and-transgender/\#sthash.sPsa8ki5.dpuf Accessed November 27, 2015.

4. Gates GJ, Newport F: Special Report: $3.4 \%$ of U.S. Adults Identify as LGBT: Inaugural GALLUP Findings based on more than 120,000 interviews. 2012. Available at www .gallup.com/poll/158066/special-report-adults-identify-lgbt .aspx Accessed November 27, 2015.

5. Albelda R, Badgett MVL, Schneebaum A, Gates GJ: Poverty in the lesbian, gay and bisexual community. The Williams Institute on Sexual Orientation Law and Public Policy: UCLA School of Law, 2009. Available at http:// williamsinstitute.law.ucla.edu/wp-content/uploads/AlbeldaBadgett-Schneebaum-Gates-LGB-Poverty-Report-March2009.pdf Accessed November 27, 2015.

6. Crenshaw KW: Mapping the margins: Intersectionality, identity politics, and violence against women of color. Stanford Law Rev 1991;43:1241-1299.

7. Heslin KC, Gore JL, King WD, Fox SA: Sexual orientation and testing for prostate and colorectal cancers among men in California. Med Care 2008;46:1240-1248.

8. Siegel R, Ma J, Zou Z, Jemal A: Cancer statistics, 2014. CA Cancer J Clin 2014;64:9-29.

9. Brawley OW: Avoidable cancer deaths globally. CA Cancer J Clin 2011;61:67-68.

10. The National Institutes of Health, National Cancer Institute, Division of Cancer Control \& Population Sciences: What is Cancer Surveillance? 2010. Available at http://surveillance .cancer.gov/about/ Accessed November 27, 2015.

11. Quinn GP, Sanchez JA, Sutton SK, et al.: Cancer and lesbian, gay, bisexual, transgender/transsexual, and queer/questioning (LGBTQ) populations. CA Cancer J Clin 2015;65:384-400.

12. Blosnich JR, Farmer GW, Lee JG, et al.: Health inequalities among sexual minority adults: Evidence from ten U.S. states, 2010. Am J Prev Med 2014;46:337-349.

13. Boehmer U, Ozonoff A, Miao X: An ecological analysis of colorectal cancer incidence and mortality: Differences by sexual orientation. BMC Cancer 2011;11:400.

14. Boehmer U, Ozonoff A, Miao X: An ecological approach to examine lung cancer disparities due to sexual orientation. Public Health 2012;126:605-612.

15. Boehmer U, Ozonoff A, Timm A: County-level association of sexual minority density with breast cancer incidence: Results from an ecological study. Sex Res Social Policy 2011;8:139-145.
16. Cochran SD, Mays VM: Risk of breast cancer mortality among women cohabiting with same sex partners: Findings from the National Health Interview Survey, 1997-2003. J Womens Health 2012;21:528-533.

17. Boehmer U, Miao X, Ozonoff A: Cancer survivorship and sexual orientation. Cancer 2011;107:3796-3804.

18. Cancer and the LGBT Community: Unique Perspectives from Risk to Survivorship. Edited by Boehmer U, Elk R. Switzerland: Springer International Publishing, 2015; pp. XVII, 331.

19. The Joint Commission Resources: Comprehensive Accreditation Manual for Hospitals: The Official Handbook. 2011.

20. Patient Protection and Affordable Care Act, Public Law No. 111-148, 124 Stat. 119. 2010. Available at www.gpo.gov/ fdsys/pkg/PLAW-111 publ148/pdf/PLAW-111publ148.pdf Accessed November 20, 2015.

21. Kamyck D, Baker K: Optimizing LGBT health under the Affordable Care Act: Strategies for Health Centers. 2013. National LGBT Health Education Center, A program of The Fenway Institute. Available at www.lgbthealtheducation.org/ wp-content/uploads/Brief-Optimizing-LGBT-Health-UnderACA-FINAL-12-06-2013.pdf Accessed November 27, 2015.

22. National Cancer Institute, Surveillance, Epidemiology, and End Results Program: Overview of the SEER Program. Available at http://seer.cancer.gov/about/overview.html Accessed March 26, 2015.

23. Smith DM, Gates GJ: Gay and lesbian families in the United States: Same-sex unmarried partner households. A Preliminary Analysis of 2000 United States Census Data. A Human Rights Campaign Report. August 22, 2001.

24. Edwards BK, Noone AM, Mariotto AB, et al.: Annual Report to the Nation on the status of cancer, 1975-2010, featuring prevalence of comorbidity and impact on survival among persons with lung, colorectal, breast, or prostate cancer. Cancer 2014;120:1290-1314.

25. Feldman J: Medical and surgical management of the transgender patient: What the primary care clinician needs to know. In: The Fenway Guide to Lesbian, Gay, Bisexual, and Transgender Health. Edited by Makadon H, Mayer K, Potter J, Goldhammer H. Philadelphia: American College of Physicians, 2008, pp. xvii, 526; 365-392.

26. Office of the National Coordinator for Health Information Technology: Meaningful Use Definition and Objectives. Washington, DC, 2015. Available at www.healthit.gov/ providers-professionals/meaningful-use-definition-objectives Accessed March 26, 2015.

27. Cebul RD, Love TE, Jain AK, Hebert CJ: Electronic health records and quality of diabetes care. N Engl J Med 2011; 365:825-833.

28. Cahill S, Makadon HJ: Sexual orientation and gender identity data collection update: U.S. government takes steps to promote sexual orientation and gender identity data collection through Meaningful Use Guidelines. LGBT Health 2014;1:157-160.

29. Centers for Disease Control and Prevention: Behavioral Risk Factor Surveillance System (BRFSS). Available at www .cdc.gov/brfss/ Accessed September 22, 2015.

30. Evans L, Lawler K, Sass S: Gathering sexual orientation data on statewide behavioral risk factor surveillance surveys: A call to action for states. The Fenway Institute, 2014. Available at http://fenwayfocus.org/wp-content/uploads/2014/03/ BRFSS-brief-March-20-2014-final.pdf Accessed September 22,2015 
31. NIH LGBT Research Coordinating Committee, Committee Chairs: Meredith D. Temple-O'Connor PhD, and Elizabeth Wehr, JD. Consideration of the Institute of Medicine (IOM) Report on the Health of Lesbian, Gay, Bisexual, and Transgender (LGBT) Individuals. January 3, 2013.

32. Boehmer U, Cooley TP, Clark MA: Cancer and men who have sex with men: A systematic review. Lancet Oncol 2012; 13:E545-E553.

33. Brown JP, Tracy JK: Lesbians and cancer: An overlooked health disparity. Cancer Causes Control 2008;19:1009-1020.

34. Boehmer U, Miao X, Maxwell NI, Ozonoff A: Sexual minority population density and incidence of lung, colorectal and female breast cancer in California. BMJ Open 2014;4: e004461.

35. Blosnich J, Jarrett T, Horn K: Disparities in smoking and acute respiratory illnesses among sexual minority young adults. Lung 2010;188:401-407.

36. U.S. Department of Health and Human Services: The Health Consequences of Smoking-50 Years of Progress: A Report of the Surgeon General, 2014. Available at www .surgeongeneral.gov/library/reports/50-years-of-progress/ index.html Accessed November 27, 2015.

37. Agenor M, Krieger N, Austin SB, et al.: Sexual orientation disparities in Papanicolaou test use among US women: The role of sexual and reproductive health services. Am J Public Health 2014;104:e68-e73.

38. Austin SB, Pazaris MJ, Nichols LP, et al.: An examination of sexual orientation group patterns in mammographic and colorectal screening in a cohort of U.S. women. Cancer Causes Control 2013;24:539-547.

39. Valanis BG, Bowen DJ, Bassford T, et al.: Sexual orientation and health: Comparisons in the women's health initiative sample. Arch Fam Med 2000;9:843-853.

40. Kerker BD, Mostashari F, Thorpe L: Health care access and utilization among women who have sex with women: Sexual behavior and identity. J Urban Health 2006;83:970-979.

41. Thomas C, Wootten A, Robinson P: The experiences of gay and bisexual men diagnosed with prostate cancer: Results from an online focus group. Eur J Cancer Care (Engl) 2013; 22:522-529.

42. Torbit LA, Albiani JJ, Crangle CJ, et al.: Fear of recurrence: The importance of self-efficacy and satisfaction with care in gay men with prostate cancer. Psychooncology 2015;24:691698.

43. Gilbert E, Ussher JM, Perz J, et al.: Men's experiences of sexuality after cancer: A material discursive intra-psychic approach. Cult Health Sex 2013;15:881-895.

44. Hart TL, Coon DW, Kowalkowski MA, et al.: Changes in sexual roles and quality of life for gay men after prostate cancer: Challenges for sexual health providers. J Sex Med 2014;11:2308-2317.

45. Motofei IG, Rowland DL, Popa F, et al.: Preliminary study with bicalutamide in heterosexual and homosexual patients with prostate cancer: A possible implication of androgens in male homosexual arousal. BJU Int 2011;108:110-115.

46. Wassersug RJ, Lyons A, Duncan D, et al.: Diagnostic and outcome differences between heterosexual and nonheterosexual men treated for prostate cancer. Urology 2013;82: 565-571.

47. Haaga DAF: "States-of-mind" analysis of the articulated thoughts of exsmokers. Cognitive Ther Res 1993;17:427-439.

48. Croghan CF, Moone RP, Olson AM: Friends, family, and caregiving among midlife and older lesbian, gay, bisexual, and transgender adults. J Homosex 2014;61:79-102.
49. Fredriksen-Goldsen KI, Kim HJ, Muraco A, Mincer S: Chronically ill midlife and older lesbians, gay men, and bisexuals and their informal caregivers: The impact of the social context. Sex Res Social Policy 2009;6:52-64.

50. National LGBT Cancer Network: LGBT Patient-Centered Outcomes: Cancer Survivors Teach Us How to Improve Care for All. 2013. Available at www.cancer-network.org/ downloads/lgbt-patient-centered-outcomes.pdf

51. Muraco A, Fredriksen-Goldsen K: "That's what friends do": Informal caregiving for chronically ill midlife and older lesbian, gay, and bisexual adults. J Soc Pers Relat 2011;28: 1073-1092.

52. Muraco A, Fredriksen-Goldsen KI: The highs and lows of caregiving for chronically ill lesbian, gay, and bisexual elders. J Gerontol Soc Work 2014;57:251-272.

53. Hash K: Caregiving and post-caregiving experiences of midlife and older gay men and lesbians. J Gerontol Soc Work 2006;47:121-138.

54. Shiels MS, Pfeiffer RM, Gail MH, et al.: Cancer burden in the HIV-infected population in the United States. J Natl Cancer Inst 2011;103:753-762.

55. Boehmer U, Mertz M, Timm A, et al.: Overweight and obesity in long-term breast cancer survivors: How does sexual orientation impact BMI? Cancer Invest 2011;29:220-228.

56. Hughes M, Cartwright C: LGBT people's knowledge of and preparedness to discuss end-of-life care planning options. Health Soc Care Community 2014;22:545-552.

57. Rawlings D: End-of-life care considerations for gay, lesbian, bisexual, and transgender individuals. Int $\mathbf{J}$ Palliat Nurs 2012;18:29-34.

58. Smolinski KM, Colon Y: Silent voices and invisible walls: Exploring end of life care with lesbians and gay men. J Psychosoc Oncol 2006;24:51-64.

59. Buchmueller T, Carpenter CS: Disparities in health insurance coverage, access, and outcomes for individuals in same-sex versus different-sex relationships, 2000-2007. Am J Public Health 2010;100:489-495.

60. Ponce NA, Cochran SD, Pizer JC, Mays VM: The effects of unequal access to health insurance for same-sex couples in California. Health Aff (Millwood) 2010;29:1539-1548.

61. Durso L, Baker K, Cray A: LGBT Communities and the Affordable Care Act: Findings from a National Survey. Washington, DC: Center for American Progress, 2013.

62. Grant J, Mottet L, Tanis J, et al.: Injustice at Every Turn: A Report of the National Transgender Discrimination Survey. Washington, DC: National Center for Transgender Equality and National Gay and Lesbian Task Force, 2011.

63. Gallagher CM, Hernandez CL, Walker MS: A progressive step toward healthcare equality. Healthc Exec 2012;27: 54-56.

64. Beehler GP: Confronting the culture of medicine: Gay men's experiences with primary care physicians. J Gay Lesbian Med Assoc 2001;5:135-141.

65. Eliason MJ, Dibble SL, Robertson PA: Lesbian, gay, bisexual, and transgender (LGBT) physicians' experiences in the workplace. J Homosex 2011;58:1355-1371.

66. Campo-Arias A, Herazo E, Cogollo Z: Homophobia among nursing students. Rev Esc Enferm USP 2010;44:839-843.

67. American College of Obstetricians and Gynecologists: ACOG Committee Opinion No. 428: Legal status: Health impact for lesbian couples. Obstet Gynecol 2009;113:469-472.

68. Sinding C, Barnoff L, Grassau P: Homophobia and heterosexism in cancer care: The experiences of lesbians. Canadian J Nurs Res 2004;36:170-188. 
69. Carroll NM: Optimal gynecologic and obstetric care for lesbians. Obstet Gynecol 1999;93:611-613.

70. Sherman MD, Kauth MR, Shipherd JC, Street RL, Jr: Communication between VA providers and sexual and gender minority veterans: A pilot study. Psychol Serv 2014;11: 235-242.

71. Obedin-Maliver J, Goldsmith ES, Stewart L, et al.: Lesbian, gay, bisexual, and transgender-related content in undergraduate medical education. JAMA 2011;306:971-977.

72. Moll J, Krieger P, Moreno-Walton L, et al.: The prevalence of lesbian, gay, bisexual, and transgender health education and training in emergency medicine residency programs: What do we know? Acad Emerg Med 2014;21:608-611.

73. Rutherford K, McIntyre J, Daley A, Ross LE: Development of expertise in mental health service provision for lesbian, gay, bisexual and transgender communities. Med Educ 2012;46:903-913.

74. Anderson JI, Patterson AN, Temple HJ, Inglehart MR: Lesbian, gay, bisexual, and transgender (LGBT) issues in dental school environments: Dental student leaders' perceptions. J Dent Educ 2009;73:105-118.

75. Corliss HL, Shankle MD, Moyer MB: Research, curricula, and resources related to lesbian, gay, bisexual, and transgender health in US schools of public health. Am J Public Health 2007;97:1023-1027.

76. Office of Minority Health; U.S. Department of Health and Human Services. National Standards for Culturally and Linguistically Appropriate Services in Health and Health Care: A Blueprint for Advancing and Sustaining CLAS Policy and Practice. 2013, p. 192.

77. Society for Adolescent Health and Medicine: Recommendations for promoting the health and well-being of lesbian, gay, bisexual, and transgender adolescents: A position paper of the Society for Adolescent Health and Medicine. J Adolesc Health 2013;52:506-510.

78. Hardacker CT, Rubinstein B, Hotton A, Houlberg M: Adding silver to the rainbow: The development of the nurses' health education about LGBT elders (HEALE) cultural competency curriculum. J Nurs Manag 2014;22: 257-266.

79. Kelley L, Chou CL, Dibble SL, Robertson PA: A critical intervention in lesbian, gay, bisexual, and transgender health: Knowledge and attitude outcomes among second-year medical students. Teach Learn Med 2008;20:248-253.
80. Wallick MM, Cambre KM, Townsend MH: Influence of a freshman-year panel presentation on medical students' attitudes toward homosexuality. Acad Med 1995;70:839-841.

81. Brondani MA, Paterson R: Teaching lesbian, gay, bisexual, and transgender issues in dental education: A multipurpose method. J Dent Educ 2011;75:1354-1361.

82. Rogers A, Rebbe R, Gardella C, et al:: Older LGBT adult training panels: An opportunity to educate about issues faced by the older LGBT community. J Gerontol Soc Work 2013;56:580-595.

83. Knochel KA, Croghan CF, Moone RP, Quam JK: Training, geography, and provision of aging services to lesbian, gay, bisexual, and transgender older adults. J Gerontol Soc Work 2012;55:426-443.

84. New York City Health and Hospitals Corporation: HHC Will Adopt Mandatory Cultural Competence Training for Staff to Improve the Health of Lesbian, Gay, Bisexual, Transgender New Yorkers. 2011. Available at www.nychhc .org/hhc/html/news/press-release-20110525-lgbt-training .shtml Accessed November 27, 2015.

85. Committee on Adolescence: Office-based care for lesbian, gay, bisexual, transgender, and questioning youth. Pediatrics 2013;132:198-203.

86. Committee on Health Care for Underserved Women: Committee Opinion no. 512: Health care for transgender individuals. Obstet Gynecol 2011;118:1454-1458.

87. Offen N, Smith EA, Malone RE: Is tobacco a gay issue? Interviews with leaders of the lesbian, gay, bisexual and transgender community. Cult Health Sex 2008;10:143-157.

88. Bye L, Gruskin E, Greenwood G, et al.: California Lesbians, Gays, Bisexuals, and Transgender (LGBT) Tobacco Use Survey-2004. Sacramento, CA: California Department of Health Services, 2005.

Address correspondence to: Jack E. Burkhalter, PhD Department of Psychiatry and Behavioral Sciences Memorial Sloan Kettering Cancer Center 641 Lexington Avenue 7 th Floor New York, NY 10022

E-mail: burkhalj@mskcc.org 